\title{
Evaluation of the Prevalence of Sub-Clinical Hepatic Encephalopathy in Compensated Cirrhotics
}

\author{
Dr.V.UshapadminiM.D. ${ }^{1}$, Dr.Akila.Md ${ }^{2}$, Dr.C.Vignesh ${ }^{3}$, \\ ${ }^{1 \text { senior }}$ Assistant Professor, Department of General Medicine,Coimbatore Medical College \&Hospital., \\ ${ }^{2}$ Assistant Professor, Department of General Medicine, Coimbatore Medical College \&Hospital. \\ ${ }^{3}$ post Graduate In General Medicine, Department Of General Medicine, Coimbatore \\ Medical College \& Hospital.
}

\begin{abstract}
Hepatic Encephalopathy is a leading cause of morbidity and mortality in cirrhotic patients. The advent of Positron Emission Tomography and Magnetic Resonance Spectroscopy has lead to earlier diagnosis of Hepatic encephalopathy,often at a sub clinical stage. Sub clinical hepatic encephalopathy is a distinct clinical entity now, with subtle personality changes and impairment of performance. Now with the help of few simple tests we can diagnosis sub clinical hepatic encephalopathy and treat it early enough to prevent significant morbidity and mortality. The treatment of these patients diagnosed to have sub clinical hepatic encephalopathy has brought reduction in the progression of these patients to frank encephalopathy.
\end{abstract}

\section{Introduction}

The study is about the evaluation of the prevalence of sub clinical Hepatic encephalopathy in compensated cirrhotics. The subclinical stage is evaluated by number connection tests,serum ammonia levels and electro encephalogram. The study is for the diagnosis of subclinical stage and to give treatment before it goes for decompensation and further complications.

\section{Aim Of The Study}

1. To evaluate the prevalence of performance impairment in compensated cirrhotics.

2.To evaluate the prevalence of cerebral cortical involvement in compensated cirrhotics using electroencephalography.

3.To assess the prevalence of subclinical hepatic encephalopathy in compensated cirrhotics using number connection test,EEG,\& Serum Ammonia levels.

\section{Materials And Methods}

The study was conducted in Coimbatore Medical College Hospital.The cases were selected from the general medical wards,the intensive care unit or medical Gastro enterology department.

50 cases of compensated cirrhosis were chosen,over a time span of two years. 50 healthy controls were chosen from volunteers. Only ultrasound proven cases of cirrhosis were chosen. Patients with frank encephalopathy or other signs of decompensation like ascites,jaundice,history of previous episode of encephalopathy, massive upper GI bleed, were excluded from study. Patients who developed encephalopathy during their stay in the hospital [one case] was also excluded.

Patients with other confounding illnesses like severe congestive cardiac failure or severe renal failure or severe respiratory failure were also excluded. 42 males and 8 females were finally included in the study.

A detailed history was recorded giving special emphasis to rule out any subtle performance impairment. Detailed history was also taken to probe into etiological cause of the patients cirrhosis.

A detailed clinical examination was done to rule out any signs of decompensation.Minimal ascites was not taken as an exclusion criteria. Minimal evidence of portal hypertension was also not taken as an exclusion criteria.

All the baseline investigation were done and a CNS examination carried out to ruleout other causes of encephalopathy.Patients above 75 years of age were ruled out as the incidence of dementing illnesses were high in these patients.

A number connection test was given to the patient and the control simultaneously, after proper explanation on how to complete the test. Before interpreting the results it was made sure that the patient understood the procedure properly. The time taken complete the test added to the time taken to correct the errors are noted.

An arterial blood sample was obtained from radial artery and was sent for ammonia analysis. An electro encephalogram was performed in all study subjects and in 10 healthy controls. 
The studies especially the number connection test was repeated just before discharge of the patients after treatment.

Number Connection Test:

\section{Observation}

All controls were able to complete correctly before 60 seconds.

$34 \%$ of cases were positive by this test.

The grading system commonly follows as

$0 \rightarrow 15-30$ seconds -------------- No SCHE

$1 \rightarrow 30-50$ seconds------------------High Normal

$2 \rightarrow 51-80$ seconds------------------Highly suggestive of SCHE

$3 \rightarrow 81-119$ seconds--------------- Highly suggestive of SCHE

$4 \rightarrow>120$ seconds------------------- Highly suggestive of SCHE

Prevalence Of Sche In Cirrhotics By Number Connection Test

\begin{tabular}{|l|l|l|}
\hline NCT POSITIVE & NUMBER & PERCENTAGE \\
\hline MALES & 15 & $30 \%$ \\
\hline FEMALES & 2 & $4 \%$ \\
\hline TOTAL & 17 & $34 \%$ \\
\hline
\end{tabular}

\section{Serum Ammonia:}

Arterial samples of all patients were sent for Ammonia Analysis. 15 patients whose blood was drawn for $\mathrm{ABG}$ analysis were taken as controls. None of these controls were known cirrhotic patients or suffering from hepatic encephalopathy.

The normal ammonia level standardized for the laboratory was 10-30 $\mu \mathrm{mol} / \mathrm{l}$. Any value above 30 $\mu \mathrm{mol} / \mathrm{l}$ were taken as positive. $48 \%$ of cases were positive for raised serum ammonia. One control tested positive for increased levels of serum ammonia.

Prevalence Of Sche Based On Ammonia Analysis

\begin{tabular}{|l|l|l|}
\hline $\begin{array}{l}\text { ARTERIAL AMMONIA } \\
>30 \mu \mathrm{mol} / 1\end{array}$ & NUMBER & PERCENTAGE \\
\hline MALES & 18 & $36 \%$ \\
\hline FEMALES & 6 & $12 \%$ \\
\hline TOTAL & 24 & $48 \%$ \\
\hline
\end{tabular}

Electro Encephalography:

All 50 patients and 10 controls were sent for EEG analysis.

None of them were on sedatives or any cerebro active drugs, none were epileptic.

All other causes for encephalopathy were ruled out by examination and baseline investigation.

EEG was taken as significant if any of the following were present.

1.Diffuse slowing of waves

2. High amplitude,low frequency waves.

3.Triphasic waves.

3 patients had significant findings $(6 \%)$ No controls had any of these findings.

Prevalence Of Sche Based On Eeg Analysis

\begin{tabular}{|l|l|l|}
\hline EEG CHANGES POSITIVE & NUMBER & PERCENTAGE \\
\hline MALES & 3 & $6 \%$ \\
\hline FEMALES & 0 & $0 \%$ \\
\hline TOTAL & 3 & $6 \%$ \\
\hline
\end{tabular}

Prevalence Of Sche In Cirrhotics Using A Combination Of

\begin{tabular}{|c|c|c|}
\hline NAME OF THE TESTS & NUMBER POSITIVE & PERCENTAGE \\
\hline Number connection test +EEG & $\begin{array}{lc}\text { Males } & : 3 \\
\text { Females } & : 0 \\
\text { Total } & : 3 \\
\end{array}$ & $\begin{array}{ll}\text { Males } & : 6 \% \\
\text { Females } & : 0 \% \\
\text { Total } & : 6 \% \\
\end{array}$ \\
\hline $\begin{array}{l}\text { Number connection test }+ \text { arterial } \\
\text { ammonia }\end{array}$ & $\begin{array}{ll}\text { Males } & : 15 \\
\text { Females } & : 1 \\
\text { Total } & : 16 \\
\end{array}$ & $\begin{array}{ll}\text { Males } & : 30 \% \\
\text { Females } & : 2 \% \\
\text { Total } & : 32 \% \\
\end{array}$ \\
\hline EEG+Arterial Ammonia & $\begin{array}{lc}\text { Males } & : 2 \\
\text { Females } & : 0 \\
\text { Total } & : 2 \\
\end{array}$ & $\begin{array}{lc}\text { Males } & : 4 \% \\
\text { Females } & : 0 \% \\
\text { Total } & : 4 \% \\
\end{array}$ \\
\hline NCT +Arterial Ammonia +EEG & Males & Males $\quad: 4 \%$ \\
\hline
\end{tabular}




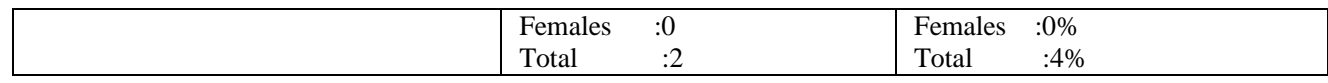

Prevalence Of Sche In Cirrhotics Males

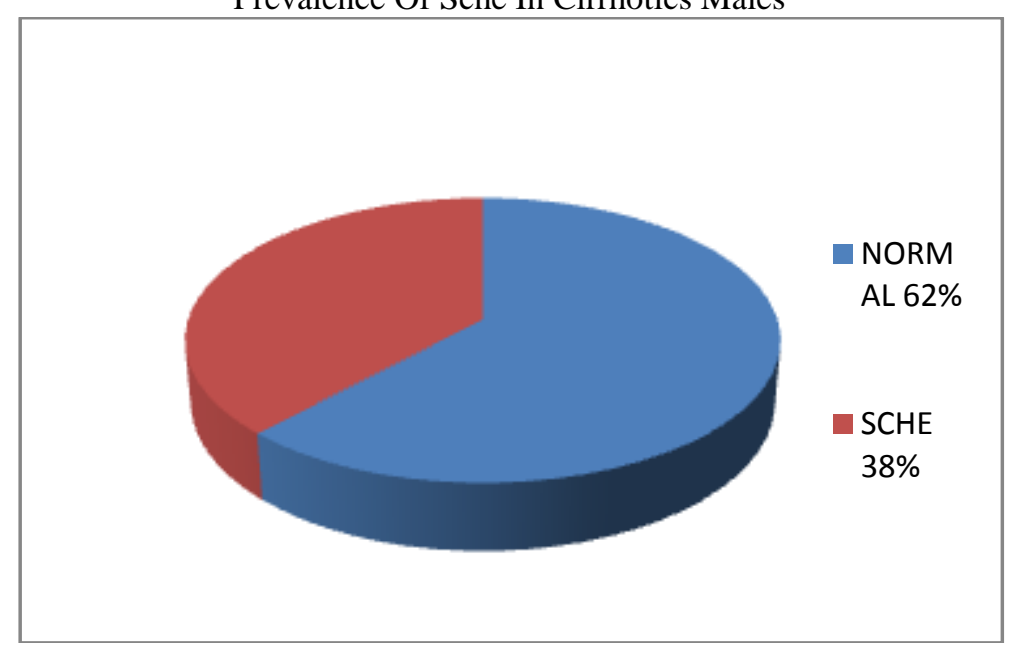

Prevalence Of Sche In Cirrhotics Females

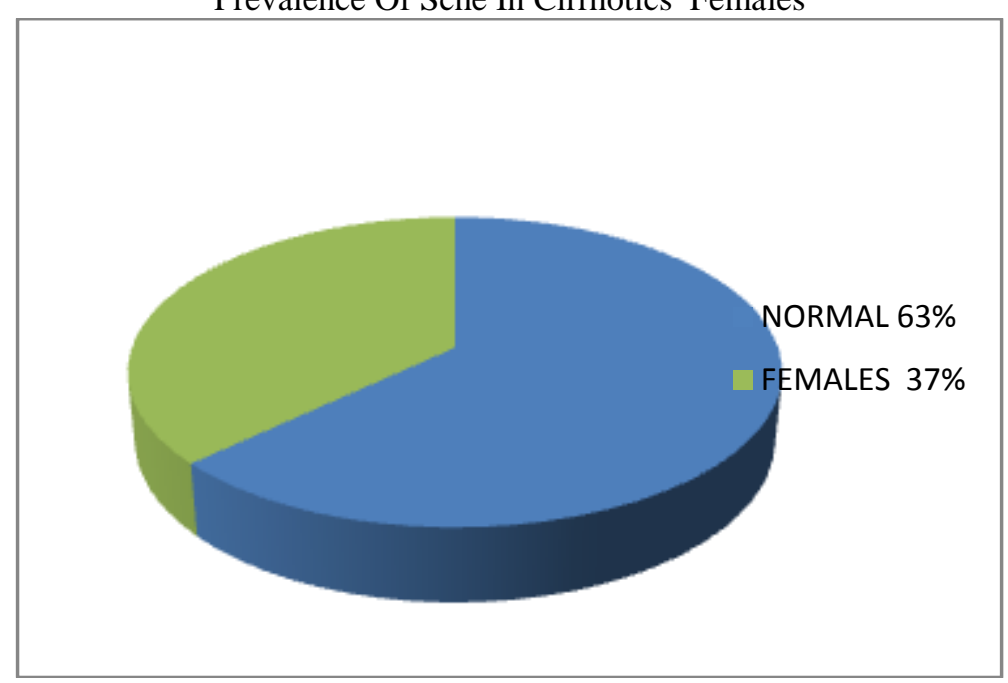

Prevalence Of Sche In Cirrhotics Males \& Females

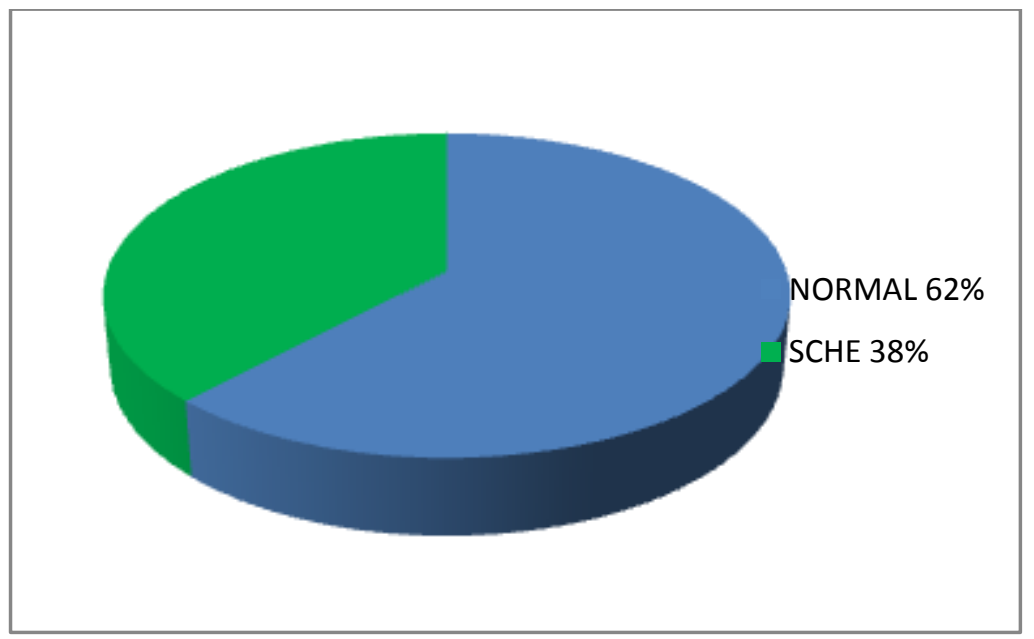




\section{Conclusions}

The prevalence of subclinical Hepatic Encephalopathy in Compensated cirrhotics in our study is $38 \%$. There is no significant difference in the prevalence rate between males [38.09\%] and females [37.5\%] Number connection test and other psychometric tests are useful as bedside tools in Sub Clinical Hepatic Encephalopathy screening. Psychometric test positivity does not correlate well with Electro Encephalo Graphic changes in the diagnosis of Sub Clinical Hepatic Encephalopathy.

\section{Bibliography}

[1]. SHEILA SHERLOCK: Hepatology $13^{\text {th }}$ Edition

[2]. Oxford Text Book Of Medicine: $6^{\text {th }}$ Edition

[3]. Harrison's Principles Of Internal Medicine $: 18^{\text {th }}$ Edition

[4]. Amodio P; Queroje ; Del Piceolof; Gatta.A: Meta Brain Diseases 2006 December;11(4) : 315-327, Sub Clinical Hepatic Encephalopathy Screening.

[5]. Subclinical Hepatic Encephalopathy Impairs Daily Functioning ,Michael Groenwegel ,Juan,C Quero Hepatology,July 1998,P 45-49 Vol.28,No.1

[6]. Portasystemic Encephalopathy Steven Schenker; Clinics In Liver Disease Vol.1,No.1,May 1997.

[7]. Screening Of Subclinical Hepatic Encephalopathy Krabbe Pf;Schalm , Hope Wc.J.Hepatology 2000 May ; 32 (5); 748-753.

[8]. The Prognostic Significance Of Sub Clinical Hepatic Encephalopathy Hartmann Et Al., Amj Gastro Enterol 2000 August ;95 (8) 2029-34.

[9]. Correlation Between Tests Used To Screen For Subclinical Hepatic Encephalopathy Manganerom,Ceccantim,Spadas Hepatogastro Enterology 2000 March-April 47(32):455-460.

[10]. Cerebral Changes In Hepatic Encephalopathy Watanabe.A. J.Gastro Enterol Hepatol 1998 July;13(7):752-760 